\title{
Antibody responses to GalC in severe and complicated childhood Guillain-Barré syndrome
}

\author{
Meyer Sauteur, Patrick M ; Huizinga, Ruth ; Tio-Gillen, Anne P ; de Wit, Marie-Claire Y ; Unger,
} Wendy W J ; Berger, Christoph ; van Rossum, Annemarie M C ; Jacobs, Bart C

\begin{abstract}
We recently presented a case series of seven children who developed severe and complicated Guillain-Barré syndrome (GBS) after infection with M. pneumoniae (Mp) (Meyer Sauteur et al., 2015). The disease was rapidly progressive and severe: one died, four had clinically defined central nervous system (CNS) involvement, and five required mechanical ventilation.
\end{abstract}

DOI: https://doi.org/10.1111/jns.12243

Posted at the Zurich Open Repository and Archive, University of Zurich

ZORA URL: https://doi.org/10.5167/uzh-142694

Journal Article

Accepted Version

Originally published at:

Meyer Sauteur, Patrick M; Huizinga, Ruth; Tio-Gillen, Anne P; de Wit, Marie-Claire Y; Unger, Wendy W J; Berger, Christoph; van Rossum, Annemarie M C; Jacobs, Bart C (2018). Antibody responses to GalC in severe and complicated childhood Guillain-Barré syndrome. Journal of the Peripheral Nervous System, 23(1):67-69.

DOI: https://doi.org/10.1111/jns.12243 


\title{
Antibody responses to GaIC in severe and complicated childhood Guillain- Barré syndrome
}

\author{
Patrick M. Meyer Sauteur ${ }^{1,2^{*}}$, Ruth Huizinga ${ }^{3}$, Anne P. Tio-Gillen ${ }^{3,4}$, Marie-Claire Y. \\ de Wit ${ }^{5}$, Wendy W.J. Unger ${ }^{1}$, Christoph Berger ${ }^{2}$, Annemarie M.C. van Rossum ${ }^{1}$, Bart \\ C. Jacobs ${ }^{3,4}$
}

1 Department of Pediatrics, Division of Pediatric Infectious Diseases and Immunology, Erasmus MCSophia Children's Hospital, University Medical Center, Rotterdam, The Netherlands

2 Division of Infectious Diseases and Hospital Epidemiology, University Children's Hospital Zurich, Zurich, Switzerland

3 Department of Immunology, Erasmus MC, University Medical Center, Rotterdam, The Netherlands

4 Department of Neurology, Erasmus MC, University Medical Center, Rotterdam, The Netherlands

5 Department of Pediatrics, Division of Pediatric Neurology, Erasmus MC-Sophia Children's Hospital, University Medical Center, Rotterdam, The Netherlands

\section{Running headline:}

Anti-GalC antibodies in severe and complicated $M$. pneumoniae-associated childhood GBS

\section{Corresponding author:}

Patrick Meyer Sauteur, MD

Division of Infectious Diseases and Hospital Epidemiology, University Children's Hospital Zurich, Steinwiesstrasse 75

$\mathrm{CH}-8032$ Zurich, Switzerland

T: +41442667896

F: +41442668072

E: patrick.meyer@kispi.uzh.ch

This article has been accepted for publication and undergone full peer review but has not been through the copyediting, typesetting, pagination and proofreading process, which may lead to differences between this version and the Version of Record. Please cite this article as doi: $10.1111 /$ jns. 12243 


\section{Key words}

Central nervous system; children; galactocerebroside; Guillain-Barré syndrome;

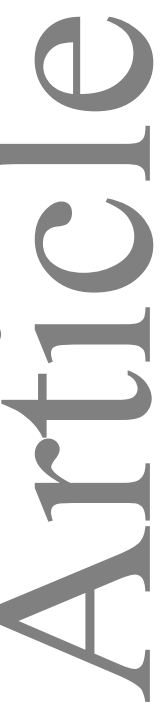

Mycoplasma pneumoniae

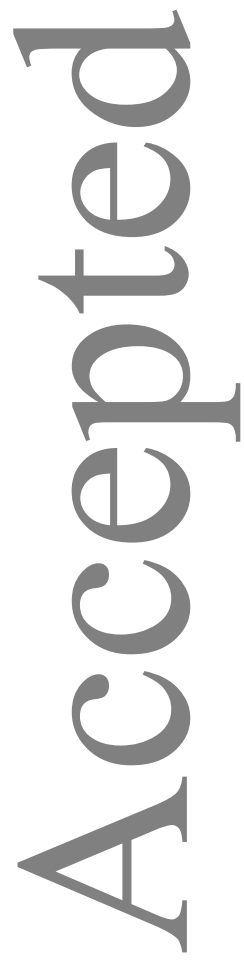




\section{Dear Editor,}

We recently presented a case series of seven children who developed severe and complicated Guillain-Barré syndrome (GBS) after infection with M. pneumoniae (Mp) (Meyer Sauteur et al., 2015). The disease was rapidly progressive and severe: one died, four had clinically defined central nervous system (CNS) involvement, and five required mechanical ventilation. Given the often relatively benign disease course of GBS after this specific type of infection (Meyer Sauteur et al., 2016) the severe and complicated GBS in this series was rather unexpected. Since we recently demonstrated that pediatric and adult GBS after $M p$ infection is associated with antibodies against galactocerebroside (GalC) (Meyer Sauteur et al., 2016) we investigated if anti-GalC antibodies were also present in these children with severe GBS.

Sera were tested for IgM and IgG antibodies to GM1, GM2, GD1a, GD1b, GQ1b, and GalC (all from Sigma-Aldrich, Zwijndrecht, the Netherlands) as previously described (Ang et al., 2000; Kuijf et al., 2005; Meyer Sauteur et al., 2016). CSF was tested for $\operatorname{lgM}$ and $\operatorname{lgG}$ to GalC at 1:10 dilution. ODs at $490 \mathrm{~nm}$ from uncoated wells (containing ethanol) were subtracted from glycolipid-coated wells. Cut-off values (0.05 for IgG and 0.03 for $\operatorname{lgM}$ ) were obtained by measuring 14 CSF samples of patients with other neurological diseases (mean OD plus 3 times the standard deviation). Some patients had previously been included in other studies (Meyer Sauteur et al., 2016; Meyer Sauteur et al., 2014; Roodbol et al., 2014).

Data were analyzed using the $\mathrm{R}$ software environment (version 3.4.1). The $\chi^{2}$ test was used to compare proportions. Two-sided $p$ values $<0.05$ were considered to be statistically significant. The study was approved by the Erasmus MC Medical Ethics Board. 
Anti-GalC IgG and/or IgM were found in six out of seven patients (86\%). Antibodies against other glycolipids were present in three of those six (anti-GM1). No antibodies were found against complexes of two glycolipids (data not shown).

Since anti-GalC IgG is specifically associated with GBS after Mp infection (Meyer Sauteur et al., 2016), we next compared the frequency of anti-GalC IgG in severe Mp-positive pediatric GBS to (1) Mp-positive pediatric GBS patients (cohort as previously described (Meyer Sauteur et al., 2016)), who did not fulfill the criteria for severe GBS (Meyer Sauteur et al., 2015) (defined as "less-severe" GBS), and (2) Mp-negative pediatric GBS (Meyer Sauteur et al., 2016). The presence of anti-GalC IgG was significantly more frequent in serum of severe $M p$-positive GBS patients (43\%, $n=3 / 7)$ than in "less-severe" Mp-positive GBS (17\%, $n=2 / 12 ; p=0.04$, Figure 1) or Mp-negative GBS $(0 \%, n=0 / 8 ; p=0.03)$.

Sufficient CSF was available in three patients with severe Mp-positive GBS. CSF anti-GalC IgG and IgM was found in three (100\%) and one (33\%), respectively. All these three did show signs and symptoms of CNS involvement.

The increased presence of anti-GalC IgG in severe Mp-positive GBS compared to "less-severe" Mp-positive GBS may suggest that these antibodies are also involved in the development of severe and complicated GBS. Anti-GalC IgG was also detected in another recent study in GBS as most frequent anti-glycolipid antibody, identified in 37\% (Kuwahara et al., 2017). The reason for the poor outcome in our series (one patient died and only two patients recovered completely) remains unclear. We (Meyer Sauteur et al., 2016) and Samukawa and coworkers (Samukawa et al., 2014) found previously no significant difference in the outcomes between antiGalC-positive and anti-GalC-negative GBS. In both studies, the anti-GalC-negative 
group consisted of different subgroups of GBS patients including Campylobacter jejuni-related anti-GM1-positive patients who are known to have a poor outcome (Rees et al., 1995). Here, all comparisons were performed within the Mp-positive GBS group. Another risk factor for poor outcome in GBS is more severe disease at entry (van den Berg et al., 2013). The development of GBS may also depend on patient-related factors that influence the susceptibility to produce cross-reactive antiglycolipid antibodies triggered by infections (Huizinga et al., 2015). The differential outcome between severe Mp-positive GBS patients of our series and "less-severe" Mp-positive GBS may suggest that our patients were more prone to produce a stronger immune response causing GBS. Indeed, the titers of anti-GalC IgG in these patients were higher compared to "less-severe" Mp-positive GBS. Apart from the role of anti-GalC antibodies, also other host factors may account for distinct outcomes in GBS (Geleijns et al., 2006; van den Berg et al., 2014).

Of the seven GBS patients in this series, four had CNS involvement (two were comatose). The relatively frequent CNS involvement in neurological diseases associated with $M p$ may be common in children. Kuwahara and coworkers (Kuwahara et al., 2017) observed that patients with CNS diseases were younger than those with GBS and variants, and hypothesized that this could possibly be a result of the relatively undeveloped blood-brain barrier in children.

In conclusion, the correlation of anti-GalC IgG with a severe and complicated disease course and presence in CSF of patients with CNS involvement suggests that these antibodies may contribute to the pathogenesis of severe Mp-associated childhood GBS. 


\section{Acknowledgements}

We thank all GBS patients and controls that volunteered in this study. P.M.M.S. is supported by the Promedica Foundation (Chur, Switzerland) and a Fellowship Award of the European Society for Paediatric Infectious Diseases (ESPID), all outside the submitted work. R.H. is funded by the GBS-CIDP Foundation International, outside the submitted work. B.C.J. is funded by the Prinses Beatrix Spierfonds, Stichting Spieren voor Spieren (W.OR 12-04), Erasmus MC (MRace), CSL-Behring, Griffols, Baxalta, and Annexon.

\section{Conflict of interest}

The authors declare that they have no conflict of interest. 


\section{References}

Ang CW, Jacobs BC, Brandenburg AH, Laman JD, van der Meche FG, Osterhaus AD, van Doorn PA (2000). Cross-reactive antibodies against GM2 and CMV-infected fibroblasts in Guillain-Barré syndrome. Neurology 54:1453-1458.

Geleijns K, Roos A, Houwing-Duistermaat JJ, van Rijs W, Tio-Gillen AP, Laman JD, van Doorn PA, Jacobs BC (2006). Mannose-binding lectin contributes to the severity of Guillain-Barré syndrome. J Immunol 177:4211-4217.

Huizinga R, van den Berg B, van Rijs W, Tio-Gillen AP, Fokkink WJ, Bakker-Jonges LE, Geleijns K, Samsom JN, van Doorn PA, Laman JD, Jacobs BC (2015). Innate Immunity to Campylobacter jejuni in Guillain-Barré Syndrome. Ann Neurol 78:343354.

Kuijf ML, van Doorn PA, Tio-Gillen AP, Geleijns K, Ang CW, Hooijkaas H, Hop WC, Jacobs BC (2005). Diagnostic value of anti-GM1 ganglioside serology and validation of the INCAT-ELISA. J Neurol Sci 239:37-44.

Kuwahara M, Samukawa M, Ikeda T, Morikawa M, Ueno R, Hamada Y, Kusunoki S (2017). Characterization of the neurological diseases associated with Mycoplasma pneumoniae infection and anti-glycolipid antibodies. J Neurol 264:467-475.

Meyer Sauteur PM, Huizinga R, Tio-Gillen AP, Roodbol J, Hoogenboezem T, Jacobs

E, van Rijn M, van der Eijk AA, Vink C, de Wit MC, van Rossum AM, Jacobs BC (2016). Mycoplasma pneumoniae triggering the Guillain-Barré syndrome: A casecontrol study. Ann Neurol 80:566-580. 
Meyer Sauteur PM, Relly C, Hackenberg A, Stahr N, Berger C, Bloemberg GV, Jacobs E, Nadal D (2014). Mycoplasma pneumoniae intrathecal antibody responses in Bickerstaff brain stem encephalitis. Neuropediatrics 45:61-63.

Meyer Sauteur PM, Roodbol J, Hackenberg A, de Wit MC, Vink C, Berger C, Jacobs E, van Rossum AM, Jacobs BC (2015). Severe childhood Guillain-Barré syndrome associated with Mycoplasma pneumoniae infection: a case series. J Peripher Nerv Syst 20:72-78.

Rees JH, Soudain SE, Gregson NA, Hughes RA (1995). Campylobacter jejuni infection and Guillain-Barré syndrome. N Engl J Med 333:1374-1379.

Roodbol J, de Wit MC, Aarsen FK, Catsman-Berrevoets CE, Jacobs BC (2014). Long-term outcome of Guillain-Barré syndrome in children. J Peripher Nerv Syst 19:121-126.

Samukawa M, Hamada Y, Kuwahara M, Takada K, Hirano M, Mitsui Y, Sonoo M, Kusunoki S, Japanese GBSSG (2014). Clinical features in Guillain-Barré syndrome with anti-Gal-C antibody. J Neurol Sci 337:55-60.

van den Berg B, Bunschoten C, van Doorn PA, Jacobs BC (2013). Mortality in Guillain-Barré syndrome. Neurology 80:1650-1654. 
van den Berg B, Walgaard C, Drenthen J, Fokke C, Jacobs BC, van Doorn PA (2014). Guillain-Barré syndrome: pathogenesis, diagnosis, treatment and prognosis. Nat Rev Neurol 10:469-482. 
